\title{
The biology of germ cell tumors in disorders of sex development
}

\begin{abstract}
Hersmus R., van Bever Y., Wolffenbuttel K.P., Biermann K., Cools M., Looijenga L.H.J.. The biology of germ cell tumors in disorders of sex development.

Clin Genet 2017: 91: 292-301. (C) John Wiley \& Sons A/S. Published by John Wiley \& Sons Ltd, 2016

Development of a malignant germ cell tumor, i.e., germ cell cancer (GCC) in individuals with disorders of sex development (DSD) depends on a number of (epi-)genetic factors related to early gonadal- and germ cell development, possibly related to genetic susceptibility. Fetal development of germ cells is orchestrated by strict processes involving specification, migration and the development of a proper gonadal niche. In this review we will discuss the early (epi-)genetic events in normal and aberrant germ cell and gonadal development. Focus will be on the formation of the precursor lesions of GCC in individuals who have DSD. In our view, expression of the different embryonic markers in, and epigenetic profile of the precursor lesions reflects the developmental stage in which these cells are blocked in their maturation. Therefore, these are not a primary pathogenetic driving force. Progression later in life towards a full blown cancer likely depends on additional factors such as a changed endocrine environment in a susceptible individual. Genetic susceptibility is, as evidenced by the presence of specific risk genetic variants (SNPs) in patients with a testicular GCC, related to genes involved in early germ cell and gonadal development.
\end{abstract}

\section{Conflict of interest}

The authors state no conflict of interest.

\author{
Remko Hersmus ${ }^{a}$, \\ Yolande van Bever ${ }^{\text {b }}$, \\ Katja P. Wolffenbuttel ${ }^{c}$, \\ Katharina Biermann ${ }^{a}$, \\ Martine Cools ${ }^{d, \dagger}$ and \\ Leendert H.J. Looijengaa, ${ }^{a}$
}

\begin{abstract}
aDepartment of Pathology, bepartment of Clinical Genetics, 'Department of Pediatric Urology, Erasmus University Medical Center, Rotterdam, The Netherlands, and dDepartment of Pediatric Endocrinology, Ghent University Hospital and Ghent University, Ghent, Belgium
\end{abstract}

†These authors shared last authorship.

Key words: disorders of sex development - germ cell cancer germ cell neoplasia in situ - germ cell tumor - gonadal development gonadoblastoma

\author{
Corresponding authors: \\ Leendert H.J. Looijenga, PhD, \\ Department of Pathology, Erasmus MC, \\ Building Be, Room 432, PO Box 2060, \\ 3000 CB Rotterdam, The Netherlands. \\ Tel.: +31107044329; \\ fax: +31107044365; \\ e-mail: l.looijenga@erasmusmc.nl \\ and \\ Martine Cools, MD, PhD, Department of \\ Pediatric Endocrinology, Ghent \\ University Hospital, Building 3K12D, \\ Room 319, De Pintelaan 185, 9000 \\ Ghent, Belgium. \\ Tel.: +3293324728; \\ fax: +3293323856 \\ e-mail: martine.cools@ugent.be
}

Received 22 August 2016, revised and accepted for publication 30 September 2016 


\section{DSD; gonadal histology and cancer risk}

sex-chromosomes, either $\mathrm{XY}$ or $\mathrm{XX}$. This leads to the development of either a male- or female- gonad originating from an initially undifferentiated bipotential structure. Presence of the Y chromosome, more specifically expression of the $S R Y$ (sex determining region on $\mathrm{Y}$ ) gene initiates testis development, while absence of a functional $\mathrm{Y}$ chromosome will in-principle lead to the development of an ovary. During the process of sex differentiation, secretion of local and hormonal factors by the fully formed testis or ovary, results in the formation of the internal and external genitalia. A disturbance in gonadal development as well as in its subsequent functionality, can lead to disorders of sex development (DSD), defined as congenital conditions in which development of chromosomal, gonadal or anatomical sex is atypical. Some of these conditions are associated with an increased risk for a germ cell cancer (GCC). Here we discuss the (epi)genetic processes involved in normal early gonadal and (embryonic) germ cell development, and focus on the pathogenesis of the precursor lesions of GCC in the context of DSD.

\section{Normal germ cell development}

Primordial germ cells (PGCs) are the precursors of gametogenesis in later life. In the mouse these cells develop in the proximal epiblast, and become detectable at embryonic day E6.5. Specification of PGCs takes place in response to bone morphogenetic protein 4 (BMP) signaling at approximately E6.0 (1). Cells expressing BLIMP1 and PRDM14, induced by BMP signaling, form a cluster of about 40 alkaline phosphatase (AP) positive PGCs at E7.25 (2-4). At E7.5 these PGCs migrate to the developing hindgut and continue at E9.5 through the mesentery and colonize the genital ridges at E10.5-12.5 $(5,6)$. Once arrived in the genital ridge (i.e. the undifferentiated gonad), PGCs are referred to as gonocytes. During this time, both in the male and female, extensive epigenetic reprogramming takes place.

Germ cell epigenetics before and after gonadal differentiation

The most notable epigenetic event taking place at these early developmental stages is genome-wide DNA demethylation, which is completed at E13.5 $(7,8)$. As a consequence of this process, parental imprints are erased, and the silenced $\mathrm{X}$ chromosome is reactivated in PGCs of female (XX) mouse embryos (9, 10). From E12.5 onwards differentiation of the mouse embryo is sex-specific (11). After PGC reprogramming, establishment of germ cell methylation marks happens in a sex-specific manner, resulting in spermand oocyte-specific methylation patterns (9). In males, re-methylation initiates as early as E14.5 in G1 arrested prospermatogonia (12), and is fully established at birth (days 19-21). The methylation patterns are maintained throughout many mitotic divisions before the cells enter meiosis (13). In females re-methylation of the gametes starts at birth during the oocyte growth phase at which time they are arrested in prophase of meiosis I (12). Besides these epigenetic events, multiple signaling pathways are activated in PGCs/gonocytes.

\section{Signaling pathways in primordial germ cells}

It is known that the KIT-KITLG (stem cell factor, $\mathrm{SCF}$ ) pathway plays an important role in the migration, proliferation and survival of mouse PGCs $(14,15)$. Recently, a number of additional relevant pathways in embryonic germ cells have been identified. It has been shown that mouse PGCs express the estrogen receptor $\alpha$ and $B$ at E11.5-12.5, and exposure to estrogens leads to phosphorylation of AKT, ERK and SRC, which regulate (de)differentiation of mouse germ cells $(16,17)$. Excess exposure to estrogens during the in vitro growth of mouse genital ridges, results in upregulation of KITLG and activation of the KIT pathway via AKT/PTEN, which in turn leads to proliferation of PGCs (18). The window of sensitivity for AKT signaling is restricted, as it is absent in germ cells in mitotic arrest and in the beginning of meiosis (17). Knock-out of PTEN in human embryonic stem cells (ES), resulted in increased cell survival and proliferation, and these cells had less differentiation capacity due to retained OCT3/4 and NANOG expression levels (19). Both PTEN and P53 independently repress expression of Nanog in mouse spermatogonial stem cells. Although these studies give more insight in the signaling pathways involved in the development of PGCs/gonocytes, their relevance for human germ cell development remains to be determined.

\section{Early gonadal differentiation, fetal testis and ovary development.}

Differentiation of the early gonad, and development of the fetal testis and ovary are presented elsewhere in this issue, and will only be discussed briefly here. In the early stages of mammalian embryonic development the undifferentiated gonads are bipotential. Formation of the early undifferentiated gonad is influenced by a number of genes, including steroidogenic factor- 1 (SF1/NR5A1), Wilms' tumor-1 (WT1), and chromobox homolog-2 (CBX2) (20-22). Studies in mice have shown that these genes play an important role in the developing gonads, and moreover, all have been associated with DSD (see below). Differentiation of the bipotential gonad into a testis begins with the specification of Sertoli cells, triggered by expression of the Y-linked $S R Y$, and subsequent SOX9 (SRY-related HMG-box, gene 9) (23-25). Sertoli cells subsequently coordinate all aspects of testis differentiation and function (26). Anti-Müllerian hormone $(\mathrm{AMH})$, and chemotactic signals produced by the early Sertoli cells causes regression of the Müllerian ducts, and ensure correct cell migration and testis cord formation $(26,27)$. The appearing fetal Leydig cells start producing testosterone (T) and insulin-like factor 3 (INSL3) inducing masculinization of the fetus (28, 29). PGCs/goncytes colonizing the early testis continue to proliferate until 17-18 weeks GA, at which time 


\section{Hersmus et al.}

they start to mature into pre-spermatogonia, and start migrating towards the basement membrane. During this time they will lose expression of embryonic markers like POU5F1, NANOG, AP, Ap2gamma and c-KIT, and will enhance expression of amongst others TSPY and VASA (DDX4) (30-33). Occasionally, a few PGCs/gonocytes, expressing embryonic markers, can still be found in the postnatal testis until 6-12 months of age (31). Until recently ovarian development was thought to be the result of a passive or default pathway, i.e. occurring in the absence of SRY expression. However, in recent years, it has been shown that ovarian development requires tightly regulated signaling pathways involving WNT family member 4 (WNT4), Forkhead Box L2 (FOXL2), Catenin beta-1 (CTNNB1) and R-spondin 1 (RSPO1) (34-37). In the fetal ovary the germ cells are called oogonia, they proliferate and their numbers increase to around $7 \times 10^{5}$ oocytes at birth. During this time embryonic markers like POU5F1 and NANOG are downregulated (38). Proliferation, meiotic entry and oocyte formation depend on the interaction with primarily granulosa cells, for which FOXL2 is essential (39). The primordial follicle consists of an individual oocyte, arrested in meiosis I, and surrounded by a layer of pre-granulosa cells (40).

It has become clear that in order to properly develop, the testis and ovary need to suppress the opposing pathways. In the XY gonad WNT4 is suppressed by FGF9 (fibroblast growth factor-9), and loss of Wnt4 in XX gonads leads to upregulation of Fgf9 and Sox9 (41). Moreover, it has been shown that Ctnnbl, Map3k1 (member of the mitogen-activated protein kinase (MAPK) pathway) and NR5Al also play a role $(35,42,43)$. Interestingly, even in adulthood testes and ovaries need to suppress activation of opposing pathways $(44,45)$.

A graphic overview of normal germ cell - and gonadal development; indicating timing, genes involved, and expression of germ cell markers is shown in Fig. 1.

\section{Disturbed germ cell development}

A disturbance in gonadal development as described above, can lead to DSD, which are categorized into three main groups based on karyotype: 46,XY DSD, 46,XX DSD, and chromosomal DSD. Each main group further consists of a spectrum of genetic diseases, hormonal disorders and syndromic forms. Defects in several genes have been shown to result in gonadal malformation and DSD, some of which will be discussed below. DSD patients with Y chromosomal material in their karyotype have the greatest risk of developing the GCC precursor lesion, with a high potential to progress to GCC, see below. We have developed a comprehensive and interactive overview of normal sex development and DSD, publically available (http://www.erasmusmc.nl/47463/ 51019/4500578/Animation).

Genetic factors involved in gonadal maldevelopment in DSD

Mutations in the genes involved in formation of the undifferentiated gonad (NR5A1, WT1 and CBX2) have

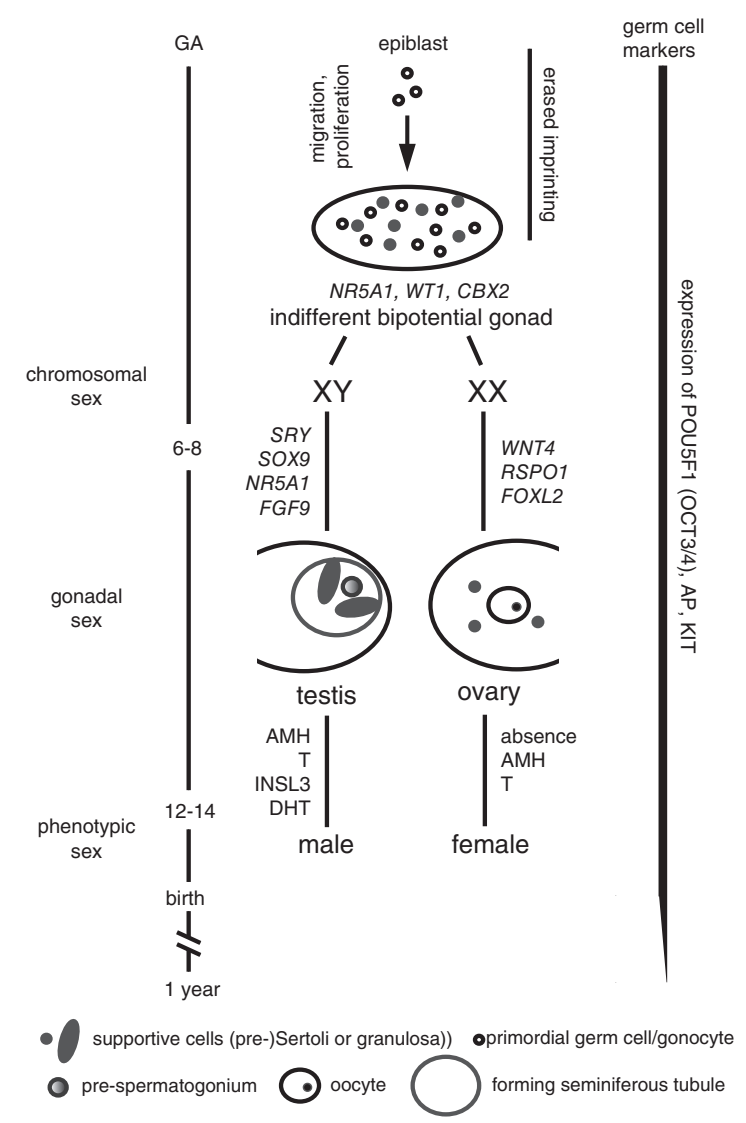

Fig. 1. Schematic representation of the earliest steps in human male and female development. Early in development in both chromosomal males and females the indifferent bipotential gonads are formed under the influence of NR5A1, WT1 and CBX2. In the XY embryo, expression of $S R Y$ initiates upregulation of SOX9, inducing a signaling cascade involving FGF9 and NR5A1 that leads to the formation of pre-Sertoli cells. These cells will further orchestrate the development of a functional testis, which in turn will, through the action of anti-Müllerian hormone $(\mathrm{AMH})$, testosterone (T), insulin-like 3 (INSL3), and dihydrotestosterone (DHT), direct the differentiation of the male internal and external genitalia. In the $\mathrm{XX}$ embryo, the absence of functional $S R Y$ directs the fate of the bipotential gonad towards the ovarian lineage. Instead of one master gene, several proteins act in parallel in female development. The absence of AMH and T leads to the differentiation of the female internal and external genitalia. The primordial germ cells (PGCs) arise early in development in the proximal epiblast, and migrate towards the genital ridges. During this time the PGCs will undergo extensive epigenetic changes, and by the time they arrive in the gonadal ridges, genomic imprinting is completely erased. A male or female specific pattern of imprinting will be established depending on the presence of a testicular or ovarian environment. In the testis the PGCs/gonocytes associated with pre-Sertoli cells, go into mitotic arrest and differentiate into pre-spermatogonia. In the ovary, gonocytes will differentiate into oocytes. During this process both in the male and female, the germ cells will lose expression of the embryonic markers POU5F1, AP, and KIT, which should be absent after the first year of life. GA: gestational age in weeks. See text for further details.

been found in patients with DSD. Human NR5A1 mutations have been associated with adrenal failure, primary ovarian insufficiency, and 46,XY complete or partial gonadal dysgenesis (a complete or partial lack of testicular development resulting in a female or ambiguous phenotype), and even 46,XX (ovo)testicular DSD (43, 46, 47). Specific WT1 mutations are known to cause 
DSD; gonadal histology and cancer risk

Denys-Drash and Frasier syndrome, characterized by an increased risk for Wilms' tumor and renal failure, respectively, and 46,XY partial or complete gonadal dysgenesis $(48,49)$. Disruption of $C b x 2$ in mice leads to defects in adrenal and splenic development, but also to varying degrees of $46, \mathrm{XY}$ sex reversal, most likely related to reduced expression of Sry (50). In humans a loss-of-function mutation in a patient with 46,XY gonadal dysgenesis has been described (51). As mentioned earlier, testicular development starts with $S R Y$ and subsequently SOX9 expression. Eighty percent of 46,XX testicular DSD cases can be attributed to translocation of $S R Y$ to one of the $\mathrm{X}$ chromosomes; and $15-20 \%$ of $46, X Y$ gonadal dysgenesis are caused by an inactivating mutation of $S R Y$ (52-54). Mutations in $S R Y$ have also been described in some cases with a mosaic sex chromosome constitution, indicating a possible role for SRY in the abnormal gonadal development in these patients $(55,56)$. Interestingly, a family has been described in which two sisters with 46,XY gonadal dysgenesis had an identical frameshift mutation in $S R Y$, which was absent in the brother, but present in the father in a mosaic constitution (57). Moreover, Shahid et al., describe a family in which the father of a DSD patient with a mosaic 45,X/46,XY karyotype displayed signs of testicular dysgenesis syndrome (TDS), and molecular analysis revealed the same deletion in the HMG-box of SRY in both (58). NROBI (DAXI) encodes an orphan nuclear receptor; and gene duplications resulting in suppression of the SRY pathway cause 46,XY DSD (59). Mutations in SOX9 have been identified in individuals with campomelic dysplasia and 46,XY DSD, and duplications of chromosome 17q, including SOX9 were found in $46, X X$ testicular DSD cases (60-62). Next to the aforementioned genes, missense mutations in desert hedgehog $(D H H)$, a signaling molecule involved in regulation of morphogenesis, cause $46, \mathrm{XY}$ complete or partial gonadal dysgenesis (63). Loss of the 9p region which includes DMRT1, a transcription factor expressed in the testis of humans and mice, is associated with gonadal dysgenesis and 46,XY DSD (64). Besides these, mutations in $M A P 3 K 1$, have been found in several cases of 46,XY DSD (65). Mutations in human GATA4, a member of the GATA family of transcription factors, have first been associated with congenital heart defects (CHD). However, several cases of 46,XY DSD, sometimes in combination with CHD have been described in families with mutations or copy number variations (CNVs) in GATA4, or its co-factor ZFPM2 (zinc finger protein, FOG family member 2) (66-68). Lastly, in an individual with 46,XY gonadal dysgenesis a deletion spanning multiple exons in the WWOX gene was found (69).

Recently, it has been shown that ovarian development involves tightly regulated pathways, and mutations in the genes involved can lead to DSD. Specifically, homozygous null mutations in WNT4 have been shown to cause 46,XX DSD (70), and heterozygous loss-of-function mutations have been described in rare cases of 46,XX women with Mayer-Rokitansky-Küster-Hauser $(\mathrm{MRKH})$ and mild virilization $(71,72)$. Loss-of-function mutations of RSPOI, a member of the R-spondin family,
Table 1. Genes involved in disorders of sex development

\begin{tabular}{|c|c|c|}
\hline Gene & $\begin{array}{c}\text { Disorder of sex } \\
\text { development (DSD) }\end{array}$ & References \\
\hline CBX2 & $46, X Y$ gonadal dysgenesis & (51) \\
\hline $\mathrm{DHH}$ & $\begin{array}{l}\text { 46,XY complete and partial } \\
\text { gonadal dysgenesis }\end{array}$ & (63) \\
\hline$D M R T 1$ & $46, X Y$ DSD & (64) \\
\hline GATA4 & 46,XY DSD & $(66,67)$ \\
\hline MAP3K1 & 46,XY DSD & $(42,65)$ \\
\hline NROB1 (DAX1) & $46, X Y$ DSD & (59) \\
\hline NR5A1 (SF1) & $\begin{array}{c}\text { 46,XY gonadal dysgenesis; } \\
\text { 46,XX ovotesticular DSD }\end{array}$ & $(43,46,47)$ \\
\hline RSPO1 & $46, X X \mathrm{DSD}$ & $(73,74)$ \\
\hline SOX9 & $\begin{array}{l}\text { 46,XY DSD; } 46, X X \text { testicular } \\
\text { DSD }\end{array}$ & $(60-62)$ \\
\hline SRY & $\begin{array}{l}\text { 46,XY gonadal dysgenesis; } \\
\text { chromosomal DSD }\end{array}$ & $(52-58)$ \\
\hline WNT4 & $46, X X \mathrm{DSD}$ & $(70-72)$ \\
\hline WT1 & $\begin{array}{l}\text { 46,XY DSD, Denys-Drash and } \\
\text { Frasier syndrome }\end{array}$ & $(48,49)$ \\
\hline WWOX & $46, X Y$ gonadal dysgenesis & (69) \\
\hline ZFPM2 & $46, X Y$ DSD & (68) \\
\hline
\end{tabular}

are associated with $S R Y$-negative 46,XX DSD $(73,74)$. Next to WNT4 and RSPOI, loss-of-function mutations in the gene encoding the transcription factor FOXL2 are associated with BPES (blepharimosis ptosis epicanthus inversus syndrome) with or without ovarian dysgenesis (75). An overview of the genes involved can be found in Table 1, and Fig. 1.

Although the number of genes implicated in DSD is growing, a molecular diagnosis cannot be made in about $75 \%$ of DSD individuals. New technologies like next generation sequencing will likely improve on this, and will uncover multigenic cases (76).

Next to these genetic factors, environmental factors play a role in gonadal and genital development. These can be due to placental insufficiency, possibly related to intra-uterine environment and endocrine disruptors, and should be considered as contributing factors to DSD-related conditions such as cryptorchidism and hypospadias $(77,78)$.

\section{Disturbed microenvironment for embryonic germ cells}

Gonadal maldevelopment as described above, or lack of hormone production or action, results in a disturbed nourishing microenvironment for the PGCs/gonocytes. In these conditions, supportive Sertoli/granulosa cells and/or Leydig/theca cells cannot provide a proper niche for the germ cells, causing a delay or block in the necessary maturational steps for full functionality as described above. This can ultimately result in infertility or even GCC, and the combination of both. Immature germ cells can be identified by the expression of the aforementioned embryonic markers (POU5F1, NANOG, etc.) at a stage beyond their normal expression window. The precursor lesions of GCC are the germ cell neoplasia in situ (GCNIS, formerly termed carcinoma in situ - CIS) or gonadoblastoma (GB), as discussed below. 


\section{Hersmus et al.}
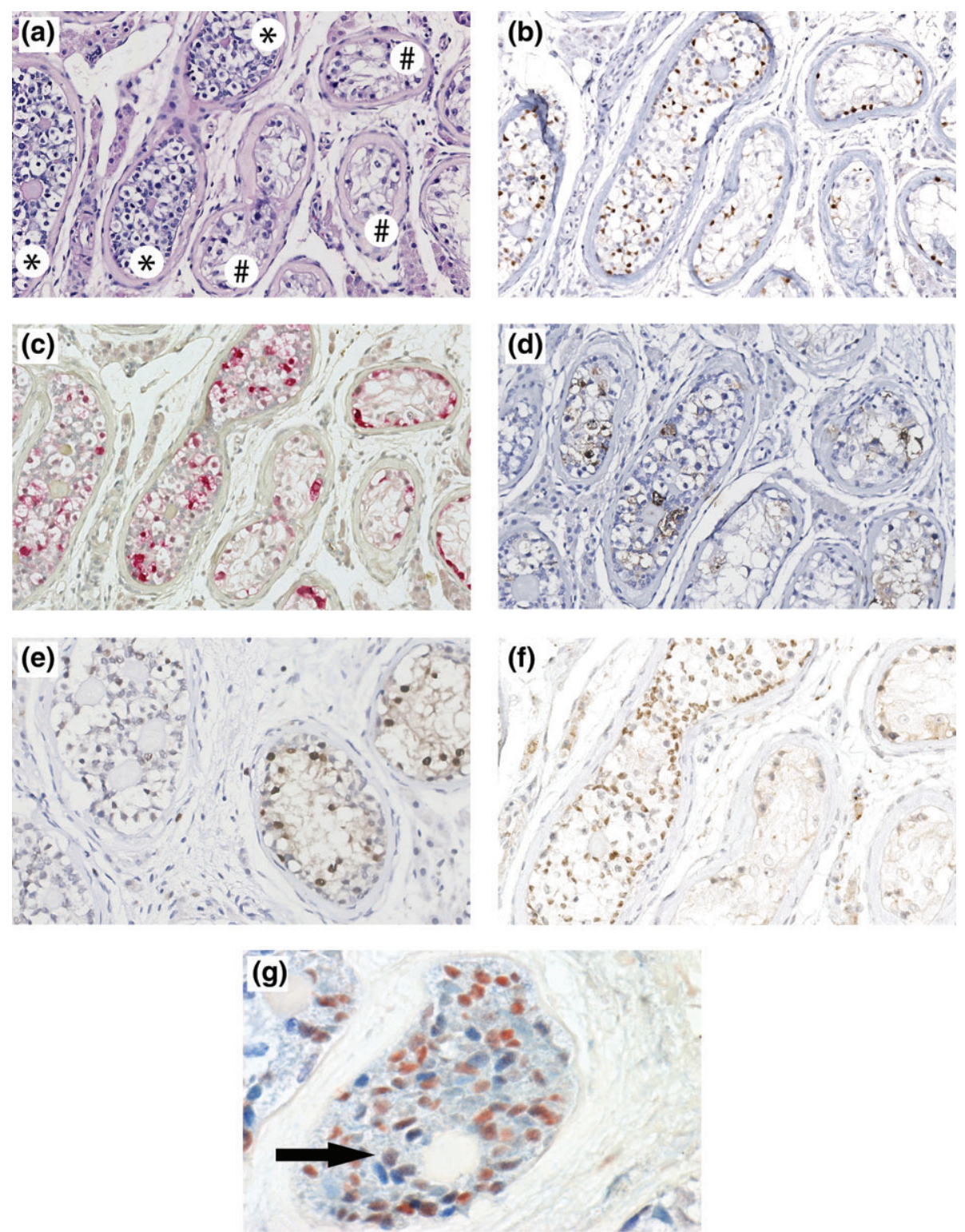

Fig. 2. Immunohistochemical staining pattern of GB and GCNIS. (a-f) Presence of GB and GCNIS in a single DSD gonad. (a) Representative hematoxylin and eosin staining. On the left side of the image the GB lesion (indicated with *), embryonic germ cells mixed with granulosa-like supportive cells, can be seen. On the right of the image GCNIS (indicated with \#), is present, with embryonic germ cells on the basal lamina associated with Sertoli cells. Both GB and GCNIS cells stain positive for (b) POU5F1 (brown staining), (c) TSPY (red staining), and (d) KITLG (brown staining). $(\mathrm{e}, \mathrm{f})$ The supportive cells in the GCNIS lesion are SOX9 positive (brown staining), and are negative for FOXL2. In the GB lesion the supportive cells stain positive for FOXL2 (brown staining) and are negative for SOX9. Adapted from (104). (g) As evidenced in the GB lesion found in another DSD patient, next to this FOXL2 only staining pattern, also the presence of both markers, sometimes even within one cell (indicated by the arrow), is observed (FOXL2: brown staining, SOX9: blue staining). Magnification: $(\mathrm{a}-\mathrm{d}) \times 200,(\mathrm{e}-\mathrm{g}) \times 400$. Slides $(\mathrm{b}-\mathrm{g})$ are counterstained with hematoxylin.

\section{Germ cell cancer}

The focus of this review being on the earliest steps in the pathogenesis of GCC, invasive GCC will only be discussed briefly. If untreated, the precursor lesion GCNIS will progress into an invasive GCC in an estimated $70 \%$ of cases, whereas around $50 \%$ of cases with GB will progress to dysgerminoma/seminoma (79-81). There are, in principle, five types of germ cell tumors, but only the type II, the seminomas/dysgerminomas and non-seminomas, are relevant in the context of DSD. In the testis, these cancers are now referred to as GCNIS-related germ cell tumors according to the latest WHO classification (82). Diagnostic markers for the invasive components can in fact be predicted based on the expected expression pattern, and knowledge of the precursor lesions either, GCNIS or GB. These are POU5F1 for both seminomas and embryonal carcinoma, independent of stage of the disease at clinical presentation and anatomical localization. In addition, SOX17 is present in seminomas and SOX2 in embryonal carcinomas, allowing a straightforward way of diagnosing these components (83). Of interest 

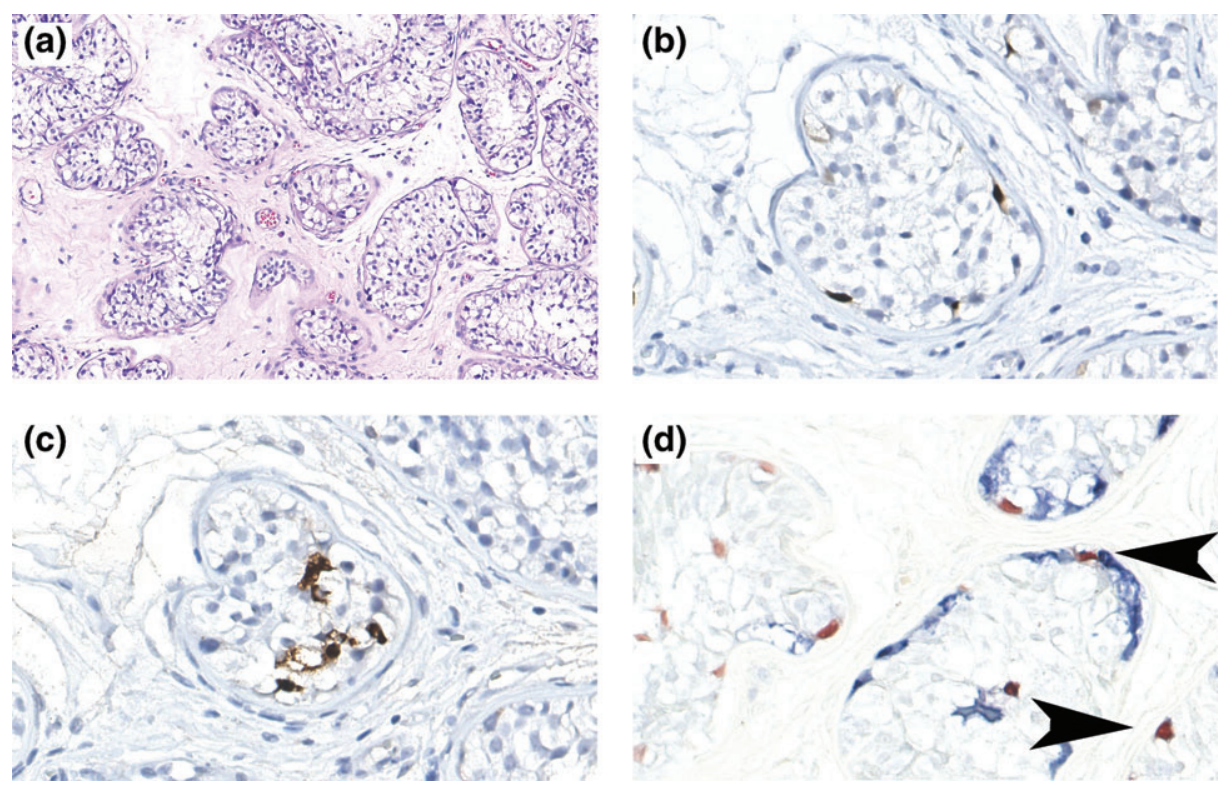

Fig. 3. Immunohistochemical staining of pre-GCNIS present in the testis of a 12-year-old presenting with severe hypospadias and cryptorchidism. (a) Representative hematoxylin and eosin staining of the area containing pre-GCNIS cells. (b) Germ cells, both pre-malignant and with maturation delay, stain positive for POU5F1 (brown staining). (c) In the staining for KITLG only pre-GCNIS cells stain positive (brown staining). (d) Double staining for POU5F1 (brown staining) and TSPY (blue staining). Note that the majority of cells are positive for either TSPY or POU5F1, and only a few cells show staining for both (arrowheads). Magnification: (a) $\times 200$, (b-d) $\times 630$. (b and c) are counterstained with hematoxylin.

is that the switch from SOX2 in embryonic stem cells (ES) towards SOX17 in PGCs has indeed recently been proven to be the driving force in the differentiation of PGCs from ES $(83,84)$. There seems to be a regulatory mechanism in which POU5F1 switches from SOX partner thereby targeting specific loci to determine cell fate (85). Based on actual data, there is no indication that genomic anomalies affecting these loci are driving cancer development, it just are persisting embryonic signaling programs. Interestingly, a defined set of micro-RNAs (miRs) show a characteristic pattern of expression in GCC (86). A functional role has been identified for miR-371-373, specifically the inhibition of LATS2, a downstream target of the P53 pathway (87), providing an explanation for the unusual presence of wild type P53 in GCC. The miR cluster $371-373$ is normally only expressed in the embryonic germ/stem cells during embryogenesis, indicating that the origin of GCC lies in early embryonic development (88). Recently, the elevated presence of this cluster of miRs in serum from testicular GCC patients has been described (89-91). However, they cannot detect patients with GCNIS only (92). A further breakthrough in understanding GCC pathogenesis came from genome-wide association studies (GWAS) in which a selected number of high risk single nucleotide polymorphisms (SNPs) were identified (93-97). None of the GWAS showed a difference in effect in seminoma $v s$ non-seminoma cases, despite sufficient sample size, supporting the presence of common oncogenic pathways in both groups. Interestingly, one SNP (rs4590952) residing in the P53 binding site of KITLG, thereby modulating its expression, is located in the same linkage disequilibrium block as the SNP found by Kanetsky et al. in 2009. (93, 98).
Studying promoter methylation of several of the associated genes found in the GWAS showed that increased promoter methylation of PDE11A, SPRY4, and $B A K 1$, and decreased promoter methylation of $K I T L G$ were significantly associated with familial testicular GCC risk (99). Another intriguing finding pointing towards susceptibility, is the presence of heterozygous germline mutations in LRCC50 in familial seminoma cases. Expression of the wild type allele is at least partially lost in these familial seminomas (100). These findings open up possible novel ways for the diagnosis and follow-up of GCC patients and for genetic susceptibility screening in GCC risk populations such as DSD (101).

\section{Germ cell cancer precursor lesions}

The precursor lesion of GCC in the testis is GCNIS (82, 102). In DSD, GB can also be found in the dysgenetic gonad, and sometimes both precursor lesions are present within the same gonad (Fig. 2) $(79,103)$. Presence of GB, possibly combined with GCNIS, found in a scrotal testis, always indicates an underlying DSD condition (104). GCNIS and GB can be distinguished by the characteristics of the supportive cells, being exclusively Sertoli cells (SOX9 positive) in GCNIS, and granulosa cells (FOXL2 positive) or a combination of both cell types, in GB (Fig. 2) (105). The level of testicular development (testicularization), as evidenced by overall morphology and SOX9 and FOXL2 expression determines the type of precursor. Malignant transformation of the germ cells requires, next to other factors described below, a susceptible environment. If the gonads have fully developed in either the female (ovary) or male (testis) direction, risk 


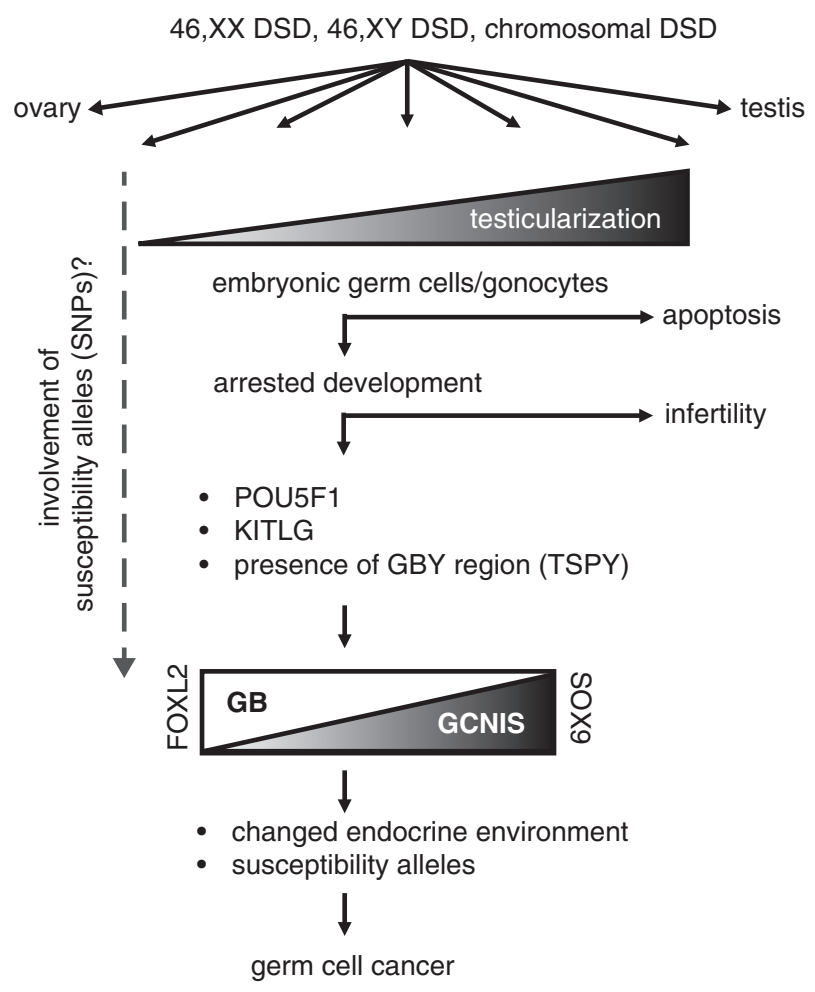

Fig. 4. Pathobiology of germ cell cancer in DSD. Individuals with DSD can have a disturbed gonadal development in which the function of the supportive Sertoli/granulosa cells is impaired. Germ cells residing in this disturbed microenvironment can undergo apoptosis, or be arrested in their development, the latter leading to infertility, or alternatively, these cells can give rise to the precursor lesions. Prolonged expression of POU5F1, KITLG and increased TSPY expression enhances the chances of survival of these germ cells. Formation of gonadoblastoma (GB) or germ cell neoplasia in situ (GCNIS) depends on the level of testicular development (testicularization), as evidenced by the expression of FOXL2 and SOX9 in the supportive cells. The expressed embryonic markers and epigenetic profile of GB and GCNIS reflect the developmental stage at which these cells are blocked, and are most likely not a driving mechanism. Development of these precursors later in life into germ cell cancer depends on a changed endocrine milieu in a susceptible individual. This susceptibility might depend on the presence of the risk SNPs (single nucleotide polymorphisms) identified in the genome-wide association studies.

for malignant transformation of the germ cells is low, as is the case in ovotesticular DSD where development of a precursor lesion is rarely seen.

GCNIS cells resemble PGCs/gonocytes both phenotypically and ultrastructural; they show the same gene and miRNA expression profiles, have a similar epigenetic status, and express the same proteins, such as POU5F1, AP, c-KIT and KITLG (31, 106-113). The germ cell component of GB and GCNIS are identical, both morphologically as well as with regard to protein expression, providing further evidence that the cell-of-origin for both GCNIS and GB is a blocked PGC/gonocyte $(114,115)$. There are a number of diagnostic markers for both precursor lesions, including, historically AP and c-KIT. It must be noted that routine use of c-KIT detection nowadays, given the sensitivity and automated detection methods, can lead to over-diagnosis (116). Interestingly, in ovarian GCC without any signs of
DSD a high frequency of c-KIT activating mutations (up to $50 \%$ ) was found (117), while individuals with DSD with a specific part of the $\mathrm{Y}$ chromosome present, the so-called GBY region (118), show expression of TSPY (testis specific protein on the Y chromosome, see below), suggesting that the c-KIT pathway is bypassed by the presence of TSPY $(117,119)$. One of the most specific marker for both GCNIS and GB to date is POU5F1 (Fig. 2) (110). Prolonged POU5F1 expression is thought to be crucial in GCC development as it allows embryonic germ cells to migrate, proliferate and survive (120). It is important to recognize, that in patients with cryptorchidism or DSD, often delayed maturation of the germ cells occurs. In these patients the germ cells still express POU5F1 after the age of 1 year, possibly leading to misinterpretation of germ cell maturation delay as GCNIS and thus over-diagnosis. KITLG has been found to be informative in distinguishing delayed mature germ cells from GCNIS: the marker being positive in GCNIS/GB cells and absent in germ cells having maturation delay (Fig. 3) (111). This is of interest in the context of the putative role of the KITLG P53 binding SNP in testicular GCC development (see above). Also the distribution and position within the seminiferous tubules of the germ cells is helpful to differentiate between the two conditions (121). Another important player in GCC development is the aforementioned TSPY gene. The physiological role of TSPY is not fully understood, but in normal testis it is thought to control mitotic proliferation of the spermatogonia. TSPY overexpression in germ cells may therefore, together with prolonged expression of POU5F1, result in the survival and proliferation of germ cells in an unfavorable milieu. Strikingly, development of GB occurs only in DSD patients with presence of the GBY region in their karyotype. This region contains several genes, but TSPY is the most likely candidate. In the fetal gonad TSPY is expressed at a stable level, but it becomes more abundant in GCNIS, GB and sometimes seminoma $(122,123)$.

In addition to the aberrant expression of genes and transcription factors associated with pluripotency, which are similar in malignant and normal fetal germ cells, the epigenetic pattern of GCNIS is, like in PGCs, associated with an open chromatin structure. GCNIS cells show hypomethylation, as evidenced by immunohistochemical staining, as does the invasive GCC component seminoma $(108,109)$. Histone modification marks in GCNIS indicate that these cells are arrested in a methylation state comparable to mouse PGCs between E7.5 and E8.25 (124). It has been found that DPPA3 (STELLA), a maternal effect gene expressed in testicular GCC and PGCs, is hypomethylated in PGCs and testicular GCC, indicating that expression in testicular GCC is linked to a retained methylation status from the PGC progenitor (125). Interestingly, analyses of 14 of the SNPs related to testicular GCC identified in the GWAS in a cohort of 52 postpubertal 46,XY DSD patients with androgen insensitivity syndrome (AIS), showed that the SNPs near KITLG (rs995030) and ATFZIP (rs2900333) distinguish between patients with and without (pre-)GCNIS (101). This implies that genetic susceptibility plays a role in GCC at least in AIS, but possibly also in other forms 


\section{DSD; gonadal histology and cancer risk}

of DSD. It remains to be clarified whether differences exist dependent on the pathogenetic stage of the disease regarding the impact of the SNPs.

\section{Concluding remarks and relevant questions for further investigation(s)}

In summary, based on our interpretation of the current data, the driving factor behind the development of GCNIS or GB in individuals with a DSD is the inappropriate or defective microenvironment in which the germ cells reside. The absence of a proper niche can result in apoptosis, or an arrested development of the germ cells, leading to infertility, or alternatively these cells can subsequently give rise to the different precursor lesions. Whether GCNIS or GB develops depends on the level of testicularization of the gonad, as evidenced by the expression of, respectively, SOX9 or FOXL2 in the supporting cells. The expression of embryonic markers, and epigenetics found in these precursor lesions is most likely not a causal mechanism, but a reflection of the developmental stage at which the cells are blocked. Whether these precursors will develop later in life into a full blown GCC likely depends on additional factors like a changed endocrine milieu in a susceptible individual. This susceptibility might be conferred by the presence of the risk SNPs identified in the different GWAS in men with a testicular GCC. In this respect, the finding that a specific SNP in a p53 responsive element of KITLG can upregulate its expression is of particular interest. A remaining question is if the identified SNPs also play a role in GCC development/risk in DSD. And if so, whether they can be used as a diagnostic tool in GCC risk stratification of DSD patients, next to the existing parameters. To summarize, a schematic representation of the pathobiology of GCC in DSD is given in Fig. 4. To be able to answer these questions and draw any meaningful conclusion, international collaboration is necessary to reach a sufficient case load of individuals with DSD in order to robustly analyze the distribution of the risk SNPs.

\section{Acknowledgements}

This work was supported by Flanders Research Foundation Senior Clinical Investigator grant (MC).

\section{References}

1. de Sousa Lopes SM, Roelen BA, Monteiro RM et al. BMP signaling mediated by ALK2 in the visceral endoderm is necessary for the generation of primordial germ cells in the mouse embryo. Genes Dev 2004: 18: $1838-1849$.

2. Ginsburg M, Snow MH, McLaren A. Primordial germ cells in the mouse embryo during gastrulation. Development 1990: 110: 521-528.

3. Ohinata Y, Payer B, O'Carroll D et al. Blimp1 is a critical determinant of the germ cell lineage in mice. Nature 2005: 436: 207-213.

4. Yamaji M, Seki Y, Kurimoto K et al. Critical function of Prdm14 for the establishment of the germ cell lineage in mice. Nat Genet 2008: 40: 1016-1022.

5. Molyneaux K, Wylie C. Primordial germ cell migration. Int J Dev Biol 2004: 48: 537-544.

6. Richardson BE, Lehmann R. Mechanisms guiding primordial germ cell migration: strategies from different organisms. Nat Rev Mol Cell Biol 2010: $11: 37-49$.
7. Guibert S, Weber M. Epigenetics: erase for a new start. Nature 2012: 492: 363-364.

8. Seisenberger S, Andrews S, Krueger $\mathrm{F}$ et al. The dynamics of genome-wide DNA methylation reprogramming in mouse primordial germ cells. Mol Cell 2012: 48: 849-862.

9. Sasaki H, Matsui Y. Epigenetic events in mammalian germ-cell development: reprogramming and beyond. Nat Rev Genet 2008: 9: 129-140.

10. Chuva de Sousa Lopes SM, Hayashi K, Shovlin TC et al. X chromosome activity in mouse XX primordial germ cells. PLoS Genet 2008: 4: e30.

11. McLaren A. Meiosis and differentiation of mouse germ cells. Symp Soc Exp Biol 1984: 38: 7-23.

12. Kota SK, Feil R. Epigenetic transitions in germ cell development and meiosis. Dev Cell 2010: 19: 675-686.

13. Davis TL, Yang GJ, McCarrey JR, Bartolomei MS. The H19 methylation imprint is erased and re-established differentially on the parental alleles during male germ cell development. Hum Mol Genet 2000: 9: 2885-2894.

14. Wylie C. Germ cells. Cell 1999: 96: 165-174.

15. Mamsen LS, Brochner CB, Byskov AG, Mollgard K. The migration and loss of human primordial germ stem cells from the hind gut epithelium towards the gonadal ridge. Int J Dev Biol 2012: 56: 771-778.

16. La Sala G, Farini D, De Felici M. Rapid estrogen signalling in mouse primordial germ cells. Exp Cell Res 2010: 316: 1716-1727.

17. Kimura T, Tomooka M, Yamano $\mathrm{N}$ et al. AKT signaling promotes derivation of embryonic germ cells from primordial germ cells. Development 2008: 135: 869-879.

18. Moe-Behrens GH, Klinger FG, Eskild W et al. Akt/PTEN signaling mediates estrogen-dependent proliferation of primordial germ cells in vitro. Mol Endocrinol 2003: 17: 2630-2638.

19. Alva JA, Lee GE, Escobar EE, Pyle AD. Phosphatase and tensin homolog regulates the pluripotent state and lineage fate choice in human embryonic stem cells. Stem Cells 2011: 29: 1952-1962.

20. Luo X, Ikeda Y, Parker KL. A cell-specific nuclear receptor is essential for adrenal and gonadal development and sexual differentiation. Cell 1994: 77: 481-490.

21. Kreidberg JA, Sariola H, Loring JM et al. WT-1 is required for early kidney development. Cell 1993: 74: 679-691.

22. Katoh-Fukui Y, Tsuchiya R, Shiroishi T et al. Male-to-female sex reversal in M33 mutant mice. Nature 1998: 393: 688-692.

23. Albrecht KH, Eicher EM. Evidence that Sry is expressed in pre-Sertoli cells and Sertoli and granulosa cells have a common precursor. Dev Biol 2001: 240: 92-107.

24. Knower KC, Kelly S, Harley VR. Turning on the male--SRY, SOX9 and sex determination in mammals. Cytogenet Genome Res 2003: 101: $185-198$.

25. Sekido R, Bar I, Narvaez V, Penny G, Lovell-Badge R. SOX9 is up-regulated by the transient expression of SRY specifically in Sertoli cell precursors. Dev Biol 2004: 274: 271-279.

26. Ostrer H, Huang HY, Masch RJ, Shapiro E. A cellular study of human testis development. Sex Dev 2007: 1: 286-292.

27. Rey R, Lukas-Croisier C, Lasala C, Bedecarras P. AMH/MIS: what we know already about the gene, the protein and its regulation. Mol Cell Endocrinol 2003: 211: 21-31.

28. Feng S, Ferlin A, Truong A et al. INSL3/RXFP2 signaling in testicular descent. Ann N Y Acad Sci 2009: 1160: 197-204.

29. O'Shaughnessy PJ, Fowler PA. Endocrinology of the mammalian fetal testis. Reproduction 2011: 141: 37-46.

30. Robinson LL, Gaskell TL, Saunders PT, Anderson RA. Germ cell specific expression of c-kit in the human fetal gonad. Mol Hum Reprod 2001: 7: 845-852.

31. Honecker F, Stoop H, de Krijger RR et al. Pathobiological implications of the expression of markers of testicular carcinoma in situ by fetal germ cells. J Pathol 2004: 203: 849-857.

32. Rajpert-De Meyts E, Hanstein R, Jorgensen $\mathrm{N}$ et al. Developmental expression of POU5F1 (OCT-3/4) in normal and dysgenetic human gonads. Hum Reprod 2004: 19: 1338-1344

33. Hoei-Hansen CE, Almstrup K, Nielsen JE et al. Stem cell pluripotency factor NANOG is expressed in human fetal gonocytes, testicular carcinoma in situ and germ cell tumours. Histopathology 2005: 47: 48-56.

34. Biason-Lauber A. WNT4, RSPO1, and FOXL2 in sex development Semin Reprod Med 2012: 30: 387-395. 


\section{Hersmus et al.}

35. Maatouk DM, DiNapoli L, Alvers A et al. Stabilization of beta-catenin in XY gonads causes male-to-female sex-reversal. Hum Mol Genet 2008: 17: 2949-2955.

36. Chassot AA, Ranc F, Gregoire EP et al. Activation of beta-catenin signaling by Rspo1 controls differentiation of the mammalian ovary. Hum Mol Genet 2008: 17: 1264-1277.

37. Vainio S, Heikkila M, Kispert A, Chin N, McMahon AP. Female development in mammals is regulated by Wnt-4 signalling. Nature 1999: 397: 405-409.

38. Kerr CL, Hill CM, Blumenthal PD, Gearhart JD. Expression of pluripotent stem cell markers in the human fetal ovary. Hum Reprod 2008: 23: 589-599.

39. Georges A, Auguste A, Bessiere L et al. FOXL2: a central transcription factor of the ovary. J Mol Endocrinol 2014: 52: R17-R33.

40. Maheshwari A, Fowler PA. Primordial follicular assembly in humans--revisited. Zygote 2008: 16: 285-296.

41. Kim Y, Kobayashi A, Sekido R et al. Fgf9 and Wnt4 act as antagonistic signals to regulate mammalian sex determination. PLoS Biol 2006: 4: e187.

42. Loke J, Pearlman A, Radi O et al. Mutations in MAP3K1 tilt the balance from SOX9/FGF9 to WNT/beta-catenin signaling. Hum Mol Genet 2014: 23: 1073-1083.

43. Baetens D, Stoop H, Peelman F et al. NR5A1 is a novel disease gene for 46, Genet Med: XX testicular and ovotesticular disorders of sex development. Genet Med 2016 (in press).

44. Uhlenhaut NH, Jakob S, Anlag K et al. Somatic sex reprogramming of adult ovaries to testes by FOXL2 ablation. Cell 2009: 139: 1130-1142.

45. Matson CK, Murphy MW, Sarver AL et al. DMRT1 prevents female reprogramming in the postnatal mammalian testis. Nature 2011: 476: $101-104$.

46. Achermann JC, Ito M, Ito M, Hindmarsh PC, Jameson JL. A mutation in the gene encoding steroidogenic factor- 1 causes XY sex reversal and adrenal failure in humans. Nat Genet 1999: 22: 125-126.

47. Lourenco D, Brauner R, Lin L et al. Mutations in NR5A1 associated with ovarian insufficiency. N Engl J Med 2009: 360: 1200-1210.

48. Pelletier J, Bruening W, Kashtan CE et al. Germline mutations in the Wilms' tumor suppressor gene are associated with abnormal urogenital development in Denys-Drash syndrome. Cell 1991: 67: 437-447.

49. Klamt B, Koziell A, Poulat F et al. Frasier syndrome is caused by defective alternative splicing of WT1 leading to an altered ratio of WT1 +/-KTS splice isoforms. Hum Mol Genet 1998: 7: 709-714.

50. Katoh-Fukui Y, Miyabayashi K, Komatsu T et al. Cbx2, a polycomb group gene, is required for Sry gene expression in mice. Endocrinology 2012: 153: 913-924.

51. Biason-Lauber A, Konrad D, Meyer M, DeBeaufort C, Schoenle EJ Ovaries and female phenotype in a girl with 46,XY karyotype and mutations in the CBX2 gene. Am J Hum Genet 2009: 84: 658-663.

52. McElreavy K, Vilain E, Abbas N et al. XY sex reversal associated with a deletion 5' to the SRY "HMG box" in the testis-determining region. Proc Natl Acad Sci USA 1992: 89: 11016-11020.

53. Hawkins JR, Taylor A, Berta P et al. Mutational analysis of SRY: nonsense and missense mutations in XY sex reversal. Hum Genet 1992 . 88: $471-474$

54. Cameron FJ, Sinclair AH. Mutations in SRY and SOX9: testis-determining genes. Hum Mutat 1997: 9: 388-395.

55. Hersmus R, Stoop H, Turbitt E et al. SRY mutation analysis by nex generation (deep) sequencing in a cohort of chromosomal disorders of sex development (DSD) patients with a mosaic karyotype. BMC Med Genet 2012: 13: 108 .

56. Canto P, de la Chesnaye E, Lopez M et al. A mutation in the 5, non-high mobility group box region of the SRY gene in patients with Turner syndrome and Y mosaicism. J Clin Endocrinol Metab 2000: 85: 1908-1911

57. Isidor B, Capito C, Paris F et al. Familial frameshift SRY mutation inherited from a mosaic father with testicular dysgenesis syndrome. J Clin Endocrinol Metab 2009: 94: 3467-3471.

58. Shahid M, Dhillon VS, Khalil HS et al. A SRY-HMG box frame shift mutation inherited from a mosaic father with a mild form of testicular dysgenesis syndrome in Turner syndrome patient. BMC Med Genet 2010: 11: 131

59. Sanlaville D, Vialard F, Thepot F et al. Functional disomy of $\mathrm{Xp}$ including duplication of DAX1 gene with sex reversal due to $\mathrm{t}(\mathrm{X} ; \mathrm{Y})(\mathrm{p} 21.2 ; \mathrm{p} 11.3)$. Am J Med Genet A 2004: 128A: 325-330.

60. Foster JW. Mutations in SOX9 cause both autosomal sex reversal and campomelic dysplasia. Acta Paediatr Jpn 1996: 38: 405-411.
61. Wagner $\mathrm{T}$, Wirth $\mathrm{J}$, Meyer $\mathrm{J}$ et al. Autosomal sex reversal and campomelic dysplasia are caused by mutations in and around the SRY-related gene SOX9. Cell 1994: 79: 1111-1120.

62. Huang B, Wang S, Ning Y, Lamb AN, Bartley J. Autosomal XX sex reversal caused by duplication of SOX9. Am J Med Genet 1999: 87: 349-353.

63. Canto P, Soderlund D, Reyes E, Mendez JP. Mutations in the desert hedgehog $(\mathrm{DHH})$ gene in patients with $46, \mathrm{XY}$ complete pure gonadal dysgenesis. J Clin Endocrinol Metab 2004: 89: 4480-4483.

64. Raymond CS, Parker ED, Kettlewell JR et al. A region of human chromosome 9p required for testis development contains two genes related to known sexual regulators. Hum Mol Genet 1999: 8: 989-996.

65. Pearlman A, Loke J, Le Caignec C et al. Mutations in MAP3K1 cause $46, X Y$ disorders of sex development and implicate a common signal transduction pathway in human testis determination. Am J Hum Genet 2010: 87: 898-904.

66. Lourenco D, Brauner R, Rybczynska M et al. Loss-of-function mutation in GATA4 causes anomalies of human testicular development. Proc Natl Acad Sci USA 2011: 108: 1597-1602.

67. White S, Ohnesorg T, Notini A et al. Copy number variation in patients with disorders of sex development due to 46, XY gonadal dysgenesis. PLoS One 2011: 6: e17793.

68. Finelli P, Pincelli AI, Russo S et al. Disruption of friend of GATA 2 gene (FOG-2) by a de novo $\mathrm{t}(8 ; 10)$ chromosomal translocation is associated with heart defects and gonadal dysgenesis. Clin Genet 2007: 71: 195-204.

69. White S, Hewitt J, Turbitt E et al. A multi-exon deletion within WWOX is associated with a 46,XY disorder of sex development. Eur J Hum Genet. 2012: 20: 348-351.

70. Mandel H, Shemer R, Borochowitz ZU et al. SERKAL syndrome: an autosomal-recessive disorder caused by a loss-of-function mutation in WNT4. Am J Hum Genet 2008: 82: 39-47.

71. Biason-Lauber A, Konrad D, Navratil F, Schoenle EJ. A WNT4 mutation associated with Mullerian-duct regression and virilization in a 46,XX woman. N Engl J Med 2004: 351: 792-798.

72. Biason-Lauber A, De Filippo G, Konrad D et al. WNT4 deficiency-a clinical phenotype distinct from the classic Mayer-Rokitansky-Kuster-Hauser syndrome: a case report. Hum Reprod 2007: 22: 224-229.

73. Parma P, Radi O, Vidal V et al. R-spondin1 is essential in sex determination, skin differentiation and malignancy. Nat Genet 2006: 38 : 1304-1309.

74. Tomaselli S, Megiorni F, De Bernardo C et al. Syndromic true hermaphroditism due to an R-spondin1 (RSPO1) homozygous mutation. Hum Mutat 2008: 29: 220-226.

75. Crisponi L, Deiana M, Loi A et al. The putative forkhead transcription factor FOXL2 is mutated in blepharophimosis/ptosis/epicanthus inversus syndrome. Nat Genet 2001: 27: 159-166.

76. Baxter RM, Arboleda VA, Lee $\mathrm{H}$ et al. Exome sequencing for the diagnosis of 46,XY disorders of sex development. J Clin Endocrinol Metab 2015: 100: E333-E344

77. Wohlfahrt-Veje C, Main KM, Skakkebaek NE. Testicular dysgenesis syndrome: foetal origin of adult reproductive problems. Clin Endocrinol (Oxf) 2009: 71: 459-465.

78. Kalfa N, Philibert P, Baskin LS, Sultan C. Hypospadias: interactions between environment and genetics. Mol Cell Endocrinol 2011: 335: 89-95.

79. Scully RE. Gonadoblastoma. A review of 74 cases. Cancer 1970: 25: 1340-1356.

80. Giwercman A, Muller J, Skakkebaek NE. Prevalence of carcinoma in situ and other histopathological abnormalities in testes from 399 men who died suddenly and unexpectedly. J Urol 1991: 145: 77-80.

81. Dieckmann KP, Loy V. Prevalence of contralateral testicular intraepithelial neoplasia in patients with testicular germ cell neoplasms. J Clin Oncol 1996: 14: 3126-3132.

82. Berney DM, Looijenga LH, Idrees $\mathrm{M}$ et al. Germ cell neoplasia in situ (GCNIS): evolution of the current nomenclature for testicular pre-invasive germ cell malignancy. Histopathology 2016: 69: $7-10$.

83. de Jong J, Stoop H, Gillis AJ et al. Differential expression of SOX17 and SOX2 in germ cells and stem cells has biological and clinical implications. J Pathol 2008: 215: 21-30.

84. Irie N, Weinberger L, Tang WW et al. SOX17 is a critical specifier of human primordial germ cell fate. Cell 2015: 160: 253-268. 


\section{DSD; gonadal histology and cancer risk}

85. Aksoy I, Jauch R, Chen J et al. Oct4 switches partnering from Sox 2 to Sox 17 to reinterpret the enhancer code and specify endoderm. EMBO J 2013: 32: 938-953.

86. Gillis AJ, Stoop HJ, Hersmus R et al. High-throughput microRNAome analysis in human germ cell tumours. J Pathol 2007: 213: 319-328.

87. Voorhoeve PM, le Sage C, Schrier M et al. A genetic screen implicates miRNA-372 and miRNA-373 as oncogenes in testicular germ cell tumors. Cell 2006: 124: 1169-1181.

88. Suh MR, Lee Y, Kim JY et al. Human embryonic stem cells express a unique set of microRNAs. Dev Biol 2004: 270: 488-498.

89. Belge G, Dieckmann KP, Spiekermann M, Balks T, Bullerdiek J. Serum levels of microRNAs miR-371-3: a novel class of serum biomarkers for testicular germ cell tumors? Eur Urol 2012: 61: 1068-1069.

90. Murray MJ, Coleman N. Testicular cancer: a new generation of biomarkers for malignant germ cell tumours. Nat Rev Urol 2012: 9: $298-300$.

91. Rijlaarsdam MA, van Agthoven T, Gillis AJM et al. Identification of known and novel germ cell cancer-specific (embryonic) miRs in serum by high-throughput profiling. Andrology 2015: 3: 85-91.

92. van Agthoven T, Looijenga LH. Accurate primary germ cell cancer diagnosis using serum based microRNA detection (ampTSmiR test). Oncotarget 2016 (in press).

93. Kanetsky PA, Mitra N, Vardhanabhuti S et al. Common variation in KITLG and at 5q31.3 predisposes to testicular germ cell cancer. Nat Genet 2009: 41: 811-815.

94. Rapley EA, Turnbull C, Al Olama AA et al. A genome-wide association study of testicular germ cell tumor. Nat Genet 2009: 41: 807-810.

95. Turnbull C, Rapley EA, Seal S et al. Variants near DMRT1, TERT and ATF7IP are associated with testicular germ cell cancer. Nat Genet 2010: 42: 604-607.

96. Chung CC, Kanetsky PA, Wang Z et al. Meta-analysis identifies four new loci associated with testicular germ cell tumor. Nat. Genet. 2013: 45: 680-685.

97. Kanetsky PA, Mitra N, Vardhanabhuti S et al. A second independent locus within DMRT1 is associated with testicular germ cell tumor susceptibility. Hum Mol Genet 2011: 20: 3109-3117.

98. Zeron-Medina J, Wang X, Repapi E et al. A polymorphic p53 response element in KIT ligand influences cancer risk and has undergone natural selection. Cell 2013: 155: 410-422.

99. Mirabello L, Kratz CP, Savage SA, Greene MH. Promoter methylation of candidate genes associated with familial testicular cancer. Int J Mol Epidemiol Genet 2012: 3: 213-227.

100. Basten SG, Davis EE, Gillis AJ et al. Mutations in LRRC50 predispose zebrafish and humans to seminomas. PLoS Genet 2013: 9: e1003384.

101. Cools M, Wolffenbuttel KP, Hersmus R et al. Malignant testicular germ cell tumors in postpubertal individuals with androgen insensitivity: prevalence, pathology and relevance of single nucleotide polymorphism-based susceptibility profiling. Mod Pathol 2016 (in press).

102. Moch H, Cubilla AL, Humphrey PA, Reuter VE, Ulbright TM. The 2016 WHO classification of tumours of the urinary system and male genital organs-part A: renal, penile, and testicular tumours. Eur Urol 2016: 70: 93-105.

103. Hersmus R, de Leeuw BH, Wolffenbuttel KP et al. New insights into type II germ cell tumor pathogenesis based on studies of patients with various forms of disorders of sex development (DSD). Mol Cell Endocrinol 2008: 291: 1-10

104. Hersmus R, Stoop H, White SJ et al. Delayed recognition of disorders of sex development (DSD): a missed opportunity for early diagnosis of malignant germ cell tumors. Int J Endocrinol 2012: 2012: 671209

105. Hersmus R, Kalfa N, de Leeuw B et al. FOXL2 and SOX 9 as parameters of female and male gonadal differentiation in patients with various forms of disorders of sex development (DSD). J Pathol 2008: 215: 31-38.

106. Novotny GW, Belling KC, Bramsen JB et al. MicroRNA expression profiling of carcinoma in situ cells of the testis. Endocr Relat Cancer 2012: 19: 365-379.
107. Sonne SB, Almstrup K, Dalgaard M et al. Analysis of gene expression profiles of microdissected cell populations indicates that testicular carcinoma in situ is an arrested gonocyte. Cancer Res 2009: 69: 5241-5250.

108. Netto GJ, Nakai Y, Nakayama M et al. Global DNA hypomethylation in intratubular germ cell neoplasia and seminoma, but not in nonseminomatous male germ cell tumors. Mod Pathol 2008: 21: $1337-1344$.

109. Wermann H, Stoop H, Gillis AJ et al. Global DNA methylation in fetal human germ cells and germ cell tumours: association with differentiation and cisplatin resistance. J Pathol 2010: 221: 433-442.

110. Looijenga LH, Stoop H, de Leeuw HP et al. POU5F1 (OCT3/4) identifies cells with pluripotent potential in human germ cell tumors. Cancer Res 2003: 63: 2244-2250.

111. Stoop H, Honecker F, van de Geijn GJ et al. Stem cell factor as a novel diagnostic marker for early malignant germ cells. J Pathol 2008: 216 ; 43-54.

112. Almstrup K, Ottesen AM, Sonne SB et al. Genomic and gene expression signature of the pre-invasive testicular carcinoma in situ. Cell Tissue Res 2005: 322: 159-165.

113. Looijenga LH, Verkerk AJ, Dekker MC et al. Genomic imprinting in testicular germ cell tumours. APMIS 1998: 106: 187-195; discussion 196-187.

114. Jorgensen N, Muller J, Jaubert F, Clausen OP, Skakkebaek NE. Heterogeneity of gonadoblastoma germ cells: similarities with immature germ cells, spermatogonia and testicular carcinoma in situ cells. Histopathology 1997: 30: 177-186.

115. Cools M, Stoop H, Kersemaekers AM et al. Gonadoblastoma arising in undifferentiated gonadal tissue within dysgenetic gonads. J Clin Endocrinol Metab 2006: 91: 2404-2413.

116. Biermann K, Stoop H, Looijenga L. c-KIT protein expression does not discriminate neoplastic from non-neoplastic intratubular germ cells. Histopathology 2012: 60: 1017-1019.

117. Hersmus R, Stoop H, van de Geijn GJ et al. Prevalence of c-KIT mutations in gonadoblastoma and dysgerminomas of patients with disorders of sex development (DSD) and ovarian dysgerminomas. PLoS One 2012: 7: e43952.

118. Page DC. Hypothesis: a Y-chromosomal gene causes gonadoblastoma in dysgenetic gonads. Development 1987: 101: 151-155.

119. Hoei-Hansen CE, Kraggerud SM, Abeler VM et al. Ovarian dysgerminomas are characterised by frequent KIT mutations and abundant expression of pluripotency markers. Mol Cancer 2007: 6: 12

120. Cools M, Looijenga L, Wolffenbuttel K, Drop S. Disorders of sex development: update on the genetic background, terminology and risk for the development of germ cell tumors. World J Pediatr 2009: 5: 93-102.

121. Cools M, van Aerde K, Kersemaekers AM et al. Morphological and immunohistochemical differences between gonadal maturation delay and early germ cell neoplasia in patients with undervirilization syndromes. J Clin Endocrinol Metab 2005: 90: 5295-5303.

122. Li Y, Vilain E, Conte F, Rajpert-De Meyts E, Lau YF. Testis-specific protein Y-encoded gene is expressed in early and late stages of gonadoblastoma and testicular carcinoma in situ. Urol Oncol 2007: 25 : $141-146$.

123. Kersemaekers AM, Honecker F, Stoop $\mathrm{H}$ et al. Identification of germ cells at risk for neoplastic transformation in gonadoblastoma: an immunohistochemical study for OCT3/4 and TSPY. Hum Pathol 2005: 36: $512-521$

124. Almstrup K, Nielsen JE, Mlynarska O et al. Carcinoma in situ testis displays permissive chromatin modifications similar to immature foetal germ cells. Br J Cancer 2010: 103: 1269-1276.

125. Killian JK, Dorssers LCJ, Trabert B et al. Imprints and DPPA3 are bypassed during pluripotency- and differentiation-coupled methylation reprogramming in testicular germ cell tumors. Genome Res 2016 (in press). 